\title{
COLLABORATIVE PRACTICE RESEARCH
}

\author{
Lars Mathiassen \\ Aalborg University \\ Denmark
}

\begin{abstract}
This paper reports from a systems development research tradition, which emphasizes relating research activities to practice and establishing fruitful collaboration between groups of researchers and practitioners. The paper describes and evaluates a specific research project in which a large group of researchers and practitioners worked together to understand, support, and improve systems development practice over a period of three years. The case is used to reflect on the research goals, approaches, and results involved in this tradition for researching systems development practice. A combined approach - based on action research, experiments, and conventional practice studies-is suggested as one practical way to strike a useful balance between relevance and rigor in practice research. The paper concludes with a general discussion of the relation between research and practice as well as advice on how to design collaborative research efforts.
\end{abstract}

Keywords: Systems development, research, practice, collaboration

\section{Introduction}

The Information Systems discipline has for quite some time been preoccupied with improving the ways in which we do research. This concern for research methodology has played a major role in maturing the discipline and has resulted in a rich discussion of different approaches (Boland and Hirschheim 1987; Cash et al. 1989; Galliers 1991;

The original version of this chapter was revised: The copyright line was incorrect. This has been corrected. The Erratum to this chapter is available at DOI: 10.1007/978-0-387-35505-4_33 
Galliers and Land 1987; Lee, Liebenau, and DeGross 1997; McFarlan 1984; Mumford et al. 1985; Nissen, Klein, and Hirschheim 1991). In our efforts to become a respected research discipline, we have also established an impressive portfolio of scientific journals and international conferences that serve as the primary media for publishing research findings. Our discussions of research methodology have, therefore, concentrated on how to support researchers in designing dedicated research activities that lead to good scientific papers.

A number of scholars within our discipline have recently made a strong plea for more relevance without abandoning rigor (Applegate 1999). Benbasat and Zmud (1999) recommend ways to increase the relevance of our research by reconsidering topic selection, the purpose and content of the articles we write, the readability of an article, and the reviewing process. Davenport and Markus (1999) suggest more radical interventions that challenge core academic values around research rigor, publication outlets and audiences, and consulting. Lyytinen (1999) supports such a broader view and encourages us to critically rethink the institutional policies and incentive schemes that govern research, the organization of research groups, the professional image of Information Systems researchers, and, last but not least, the ways in which we study practice. Lee (1999) argues for a need to go beyond a positivistic research tradition.

This paper addresses many of these concerns by reporting from a research tradition that for some years has studied practice in close collaborations between groups of practitioners and researchers. Such a collaborative approach introduces new interpretations of the relation between research and practice, it raises many practical problems and conflicts, and it is not easily implemented into any institutional setting. The purpose of the present argument is, therefore, not to criticize well-established research traditions. Rather, it is to critically rethink key issues in designing practice research based on experiences from a particular tradition in which relevance is emphasized without abandoning rigor.

Starting from research methods, or from the point of view of writing scientific papers, invites us to think in terms of choosing between different research methods (see, for example, Galliers 1991; Galliers and Land 1987). This viewpoint is extremely useful when one wants to understand the variety and the relative strengths and weaknesses of available research methods. But when designing and organizing research projects based on collaboration with practitioners, the challenge is not so much which methods to choose. Rather, it is to find practical ways to combine qualitatively different research approaches to support the diverse, and partly contradictory, goals involved in such an effort. In the following, I am in favor of such a combined approach-based on action research, experiments, and conventional practice studies - as one practical way to strike a useful balance between relevance and rigor in practice research.

Section 2 presents and discusses a particular research project in which a large group of researchers and practitioners worked together to understand, support, and improve systems development practice based on the so-called Software Process Improvement (SPI) paradigm (see, for example, Emam, Drouin, and Melo 1998; Humphrey 1988, 1989; Kuvaja et al. 1994; Paulk et al. 1993). Based on this case and on the related tradition for doing practice research, I review classical issues and state-of-the-art literature related to research goals (section 3), research approaches (section 4), and research results (section 5). Section 6 examines the underlying view of the relation 
between research and practice and provides advice on how to design useful collaborations between researchers and practitioners. While the issues raised are of interest to Information Systems research in general, they are discussed based on experiences from the particular field of systems development.

\section{Research Practice}

The SPI project was a research collaboration involving practitioners from four software organizations and researchers from universities and technology institutes (Johansen and Mathiassen 1998). The collaboration lasted over three years (1997-1999) with a US \$4 million budget, of which half was financed by the Danish Ministries of Commerce and Research while the other half was sponsored by the participating software organizations. The project involved more than 10 researchers, each spending between $25 \%$ and $75 \%$ of their time on the project, and involved three to seven practitioners from each organization as active members of the research project.

Establishing such a research effort is in no way easy. We had good contacts with all levels of the four participating organizations, national research programs provided funding to make researchers collaborate more closely with industry, and the particular theme of the project, i.e., SPI, was known to provide attractive opportunities for software organizations. Finally, we had considerable experience in working closely with practitioners and our institutional setting was positive toward collaboration with industry. Our approach to research grew out of the Scandinavian trade union research tradition (Bjerkness and Bratteteig 1995; Nygaard and Bergo 1975), was later inspired by Checkland's approach to action research (Checkland 1981; Checkland and Scholes 1990), and has been adapted and developed since the early 1980s to suit the study of systems development practice (Mathiassen 1998a, 1998b).

The industry related mission of the project was to systematize SPI knowledge in Danish companies, to tailor and further develop the most promising models for SPI so they apply to the Danish software industry, to develop frameworks for managing, organizing, and implementing SPI activities in Danish companies, and, finally, to communicate and publish knowledge about SPI to Danish companies. These missions were addressed through research efforts in which the following research questions were addressed:

- Evaluation: How can we interpret or assess an organization's capability to develop systems, identify appropriate improvement areas and strategies, and measure the effect of the implemented improvement?

- Modeling: How can we model systems development processes, the conditions under which they are performed, and their capability to develop quality systems?

- Improvement: How can we manage, organize, and carry out initiatives that in a sustainable way improve an organizations capability to develop quality systems?

To meet this diverse set of industry and research related objectives, the project was organized as a loosely coupled system of interacting agendas each addressed by a dedicated forum of actors. The overall organization of the project is illustrated in Figure 1. 


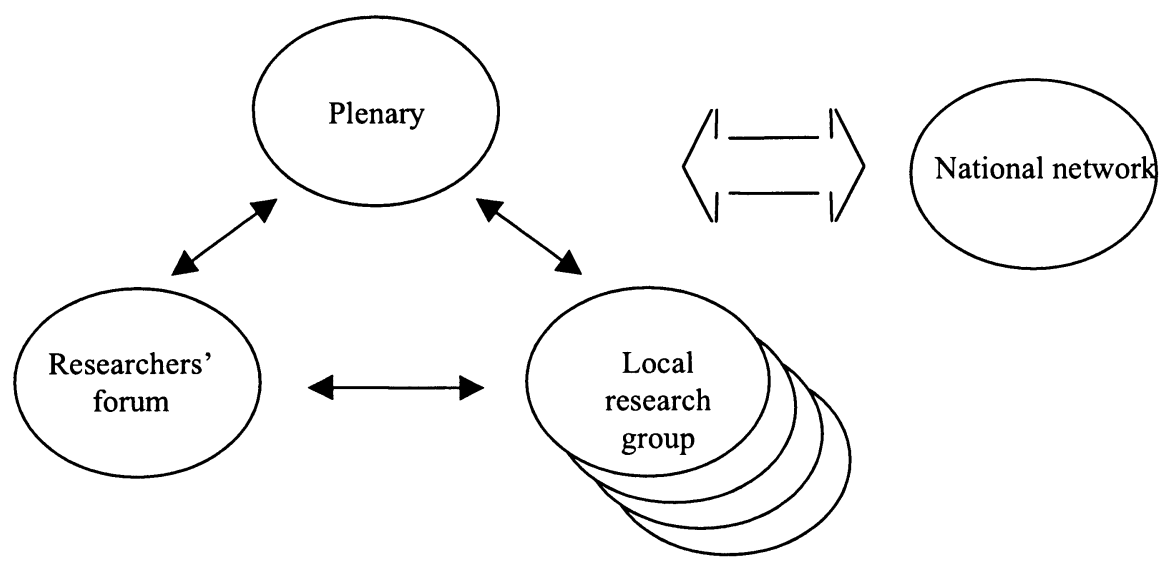

Figure 1. Overall Research Organization

First, a local research group was established to study software process improvement in each of the four software organizations (see Figure 2). This group worked tightly with the local management (both informally and formally through a steering committee), the local SPI group, and the ad hoc projects that were established to implement specific improvement initiatives. Each research group included three to seven practitioners from the software organization (normally the SPI group) and three to four external researchers. The research group met eight to 10 times a year and followed the SPI initiative closely. The group supported the software organization in adapting and using improvement approaches; it participated in some of the organization's dedicated improvement projects; and it continuously evaluated the way in which SPI knowledge was adapted, used, and further developed within the organization.

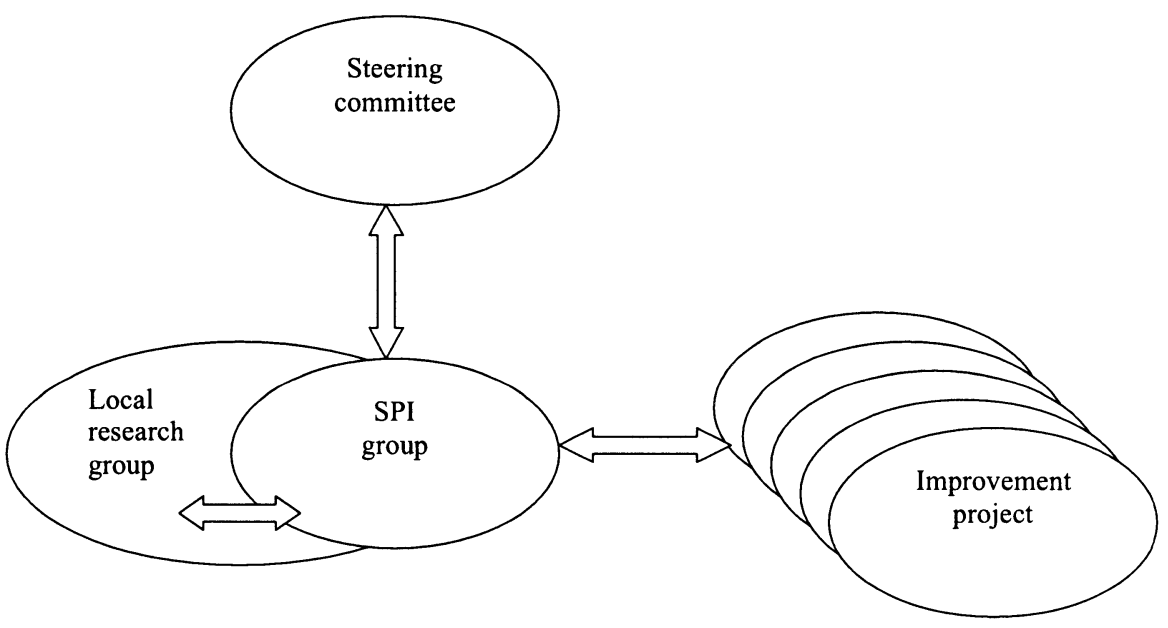

Figure 2. Local Research Organization 
Second, a plenary, consisting of the four local research groups, was formed to support interaction between the researchers and practitioners involved in the project. This plenary of 25 to 35 people met twice each year in two-day workshops where experience and knowledge were exchanged across the companies, new knowledge on process improvement was presented, ideas related to specific improvement areas were discussed, and experiences were interpreted and put into perspective through general discussions of software development, software management, and organizational learning and change.

Third, a nation-wide network was formed to support software process improvement initiatives in other organizations. More than 50 companies and 80 individuals participated in this network that met for one-day seminars three to four times a year. The project also organized or participated in a number of conferences on SPI targeting the Danish software industry.

Last, but not least, a researchers' forum was formed to stimulate publication of results and collaboration between the researchers involved in the project. The researchers' forum met for half a day six to eight times a year to identify emerging research themes, plan dedicated research initiatives, form new patterns of collaboration between researchers, discuss research approaches, present and evaluate preliminary results, and discuss relevant theoretical frameworks and related research. The researchers' forum also served as a means to support close collaboration with a number of international research colleagues. Their participation was established to improve the research process by including experiences from similar research projects and knowledge from relevant reference disciplines.

From the point of view of the individual researcher, this organization constituted a collaborative space in which dedicated research initiatives and shifting patterns of collaboration took shape as the process unfolded. Typically, each researcher participated in two local research groups, took part in all plenary meetings, and was actively involved in the researchers' forum. When adding additional ad hoc meetings related to preparation of seminars and workshops, planning of joint publications, and supervision of Ph.D. thesis work, each researcher would typically participate in one to three joint activities each week during the three year course of the project. The number of shared obligations, some of a rather practical nature, that follow from participating as a researcher in such a collaborative effort is, therefore, extremely high. However, I will argue that the opportunities to create relevant research results are at the same time extremely good.

\section{Research Goals}

Collaborative research involving both researchers and practitioners must serve different interests. In the SPI project, there was an industry-related mission together with a set of research goals; there was also an ambition to add to the body of knowledge within the systems development profession while at the same time advancing practices in each of the participating organizations. Collaborative practice research is, in this way, constantly confronted with dilemmas between practice-driven and research-driven goals and between general and specific knowledge interests. It is well known that researchers in such situations easily turn into consultants (Baskerville and Wood-Harper 1996) and it was, 
therefore, not surprising that we had to actively promote our research interests in the SPI project. SPI efforts are both demanding and exciting so the researchers were constantly encouraged to engage themselves in the practical struggle to make things happen and succeed in the four organizations. In response to this pressure, we build a strong subculture around the researchers' forum to maintain critical reflection, publication, and research methodology as key issues.

Underlying the specific goals of a collaborative practice research effort, we find a deeper level of related research goals and activities. These goals can be expressed in terms of the types of knowledge that the effort intends to develop. Adapting the framework offered by Vidgen and Braa (1997), we can distinguish between different types of knowledge as illustrated in Figure 3 (Mathiassen 1998a, 1998b). The arrows inside the triangle represent distinct, and in some respects divergent, research activities through which each type of knowledge is developed. First, to develop our understanding of systems development, we must engage in interpretations of practice. Second, to build new knowledge that can support practice, we must design normative propositions or artefacts, e.g., guidelines, standards, methods, techniques, or tools. Third, to learn what it takes to actually improve practice we must engage in different forms of social and technical intervention. Most Information Systems research restricts itself to understanding and supporting practice. A commitment to improve practice is the distinguishing feature of collaborative practice research and of action research in general (Baskerville and Wood-Harper1996).

The three goals are distinct and can be pursued in isolation, but that would seriously reduce the opportunities to learn about practice. The triangle symbolizes that the involved activities presuppose each other: we reach a deeper understanding of practice as we attempt to change it; we need to understand practice to design useful propositions; and the propositions and our interpretations of practice are ultimately tested through attempts to improve practice. This unity of the goals is a simple expression of the elements in organizational learning and change: to appreciate the situation-to invent new options - to change the situation. We find these elements in different forms and relations within theories of the field (e.g., Argyris and Schön 1978; Schein 1985) and in practical approaches as well (e.g., Checkland 1981; Checkland and Scholes 1990; Davenport 1993).

The research goals apply to different levels of practice. First, they apply to systems development. Due to the complex and dynamic nature of the discipline, systems developers need to practice reflection-in-action (Mathiassen 1998a, 1998b; Schön 1983). They must interpret the situations in which they find themselves (understand); they must develop what-if scenarios to reflect on opportunities for action (support); and they must enact some of these to establish and maintain satisfactory working situations (improve). Second, these goals and activities correspond closely to the main ingredients involved in dedicated improvement activities as expressed in the so-called IDEAL model (McFeeley 1996) for SPI (Initiate improvement effort, Diagnose current practices and form strategy for intervention, Establish specific improvement projects, Act to improve, and Learn from the initiatives). The IDEAL process represents a specific way to enact the general learning cycle expressed in the triangle: to appreciate the situation - to invent new options - to change the situation and so on. Third, the triangle expresses the types of knowledge and activities involved in collaborative practice research. Practice, improvement of practice, and practice research are in this way both similar and different in nature. We will further explicate the relation between them in Section 6 . 


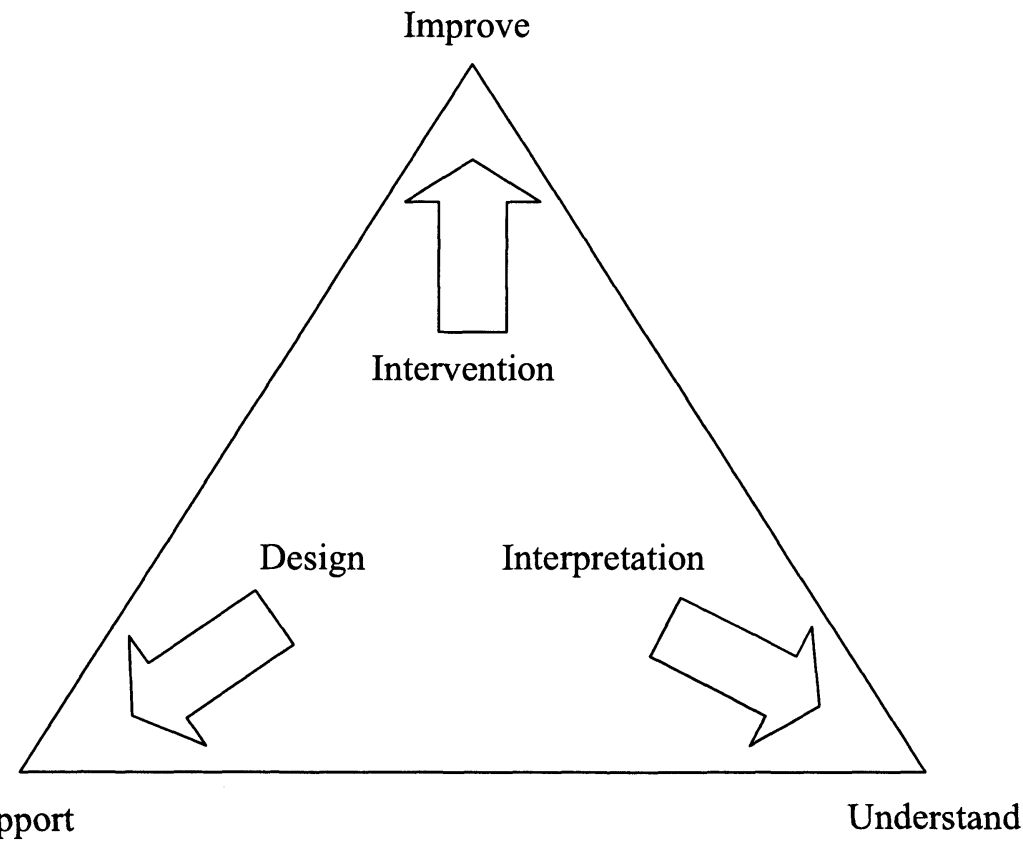

Support

Figure 3. Research Goals and Activities (Adapted from Vidgen and Braa 1997)

A closer look at the SPI project can illustrate how the goals unfold in research practice. One of the fundamental ideas in SPI is to use data-driven intervention, i.e., to base decisions on new improvement initiatives on systematically collected data about current practices. There was, therefore, a natural focus in the SPI project on activities aimed at evaluating practice. Hence the question: How can we understand, support, and improve the ways in which we evaluate systems development practice as part of SPI efforts? Various types of assessments were carried out to evaluate present practices against general norms (Andersen et al. 2000; Iversen et al. 1998), problem diagnosis was used to appreciate what the involved actors considered to be critical problems in present practices (Iversen, Nielsen, and Nørbjerg 1998), defect reports were analyzed to identify patterns of problematic behavior (Vinter 1998), and metrics programs were implemented to learn about the effect of the improvement initiatives (Iversen and Mathiassen 2000). Each of these contributions gave different priority to the three research goals. Some (Iversen et al. 1998; Iversen and Mathiasson 2000) focused on interpretations of practice (understand) and suggested lessons to guide SPI efforts (support). Others (Andersen et al. 2000; Iversen, Nielsen, and Nørberg 1998; Vinter 1998) were driven by specific ideas on how to evaluate systems development practice (support) and these were tried out and evaluated in practice (improve and understand). 


\section{Research Approaches}

Turning to research approaches we find a multiplicity of general approaches to Information Systems research together with extensive discussions of their strengths and weaknesses (Boland and Hirschheim 1987; Cash et al. 1989; Galliers 1991; Gallers and Land 1987; Lee, Liebenau, and DeGross 1997; McFarlan 1984; Mumford et al. 1985; Nissen, Klein, and Hirschheim 1991). In addition, we find a more specialised discussion of approaches to systems development research (Basili and Weiss 1984; Basili, Selby, and Hutchens 1986; Cotterman and Senn 1992; Nunamaker, Chen and Purdin 1991; Wynekoop and Russo 1993).

The main concern in collaborative practice research is to establish well functioning relations between research and practice. This is, however, far from easy to achieve. Practitioners must, on the one hand, agree to become objects of study. Practitioners must accept having meetings tape-recorded, they must engage in critical reflections of their practices, and they must be willing to report weaknesses and failures of their efforts. Researchers must, on the other hand, commit themselves to improving practice and adopt flexible research approaches as practice changes and new priorities emerge.

Ideally, we want the research process to be tightly connected to practice to get first hand information and in-depth insight. At the same time, we must structure and manage the research process in ways that produce rigorous and publishable results. Unfortunately, these two fundamental criteria do not always point in the same direction. The dilemmas related to fulfilling the two criteria can be expressed by distinguishing between three basic research approaches as illustrated in Figure 4 (Mathiassen 1998a, 1998b; MunkMadsen 1986; Nunamaker, Chen, and Purdin 1991; Wynekoop and Russo 1993 ). Each of these approaches can be practiced in a variety of ways and they all contribute to the building of knowledge on systems development.

Action research provides optimal access to practice, but it is quite difficult to control the research process. The researcher is involved in practice situations in close collaboration with practitioners and the research agenda is, therefore, strongly dependent on how practice evolves. The research activity can focus on the systems being developed, on the development processes, or on both. The strength of this approach is the strong integration of research and practice: practitioners are involved in the research process and researchers gain first-hand experience. The most significant weakness is the limited support provided to structure the research process and findings. Quite a number of recent papers have discussed the use of action research within Information Systems (Avison et al 1999; Baskerville and Wood-Harper 1996; Lau 1997; Mathiassen 1998a, 1998b; Nielsen 1999; Stowell, West, and Stansfield 1997). But the actual use of action research to systems development is documented in relatively few sources (e.g., Avison and Wood Harper 1991; Bjerknes 1991; Kaiser and Bostrom 1982; Knuth 1989; Mathiassen 1998b [Chapters 2, 10, 14, and 18]; Mumford 1983; Parnas and Clements 1986).

Experiments provide direct access to a practices that are controlled, or partly controlled, by the researchers. Such experiments can either take place in realistic settings, such as a field experiment, or in laboratory environments. A key advantage with this type of research is that the research process can be designed to focus on specific questions and issues. The disadvantage, as compared to action research, is the weaker relation to practice. Experiments are more commonly used in systems development research and a 


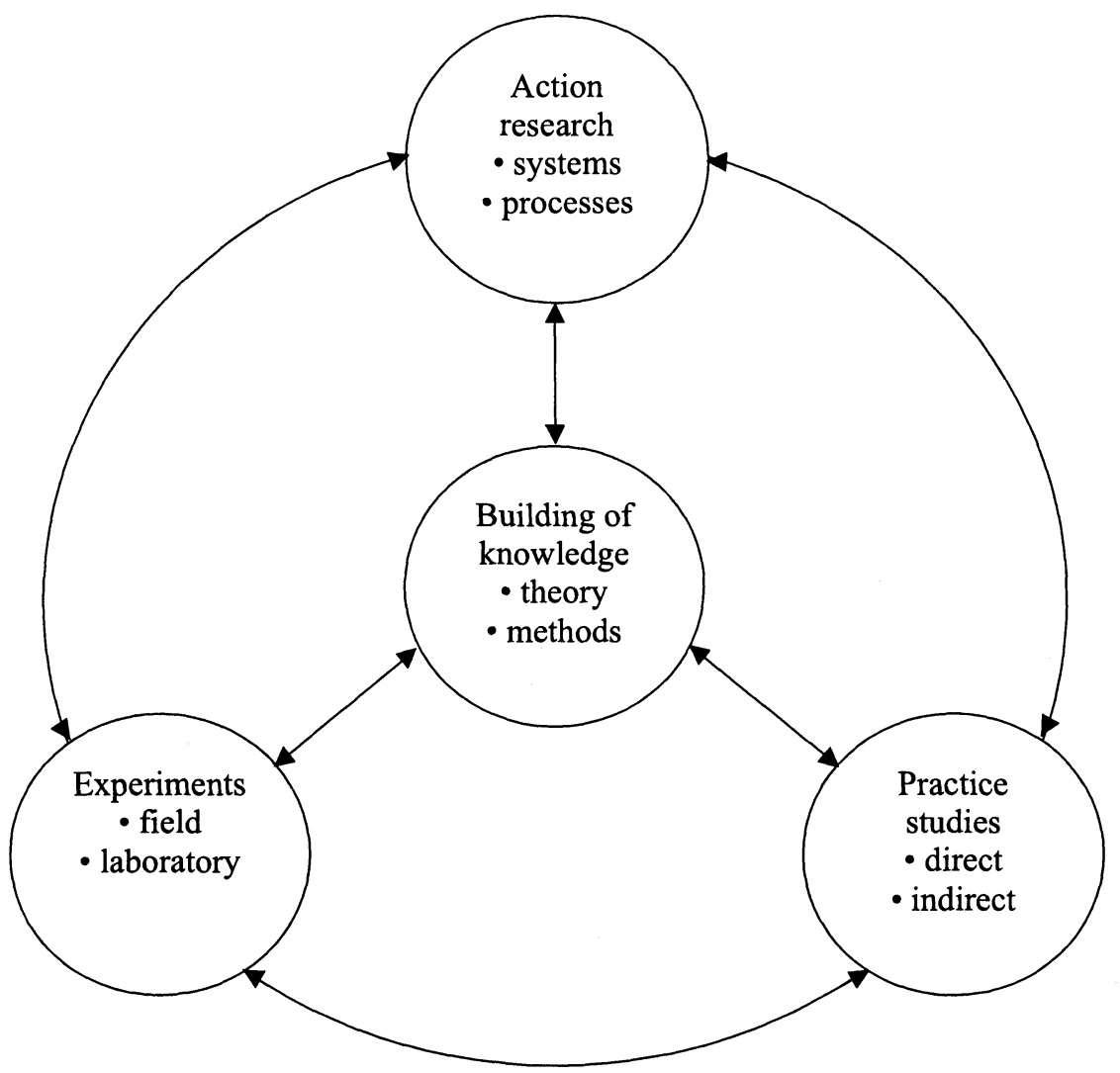

Figure 4. Approaches to Study Systems Development Practice (Adapted from Nunamaker, Chen, and Purdin 1991)

number of contributions have been reported based on this approach (e.g., Baskerville and Stage 1996; Boehm, Gray, and Seewaldt 1984; Boland 1978; Floyd 1986; Guindon, Krasner, and Curtis 1987; Mathiassen 1998b [Chapters 3 and 7]; Selby, Basili, and Baker 1987; Vitalari 1985; Vitalari and Dickson 1983).

Practice studies cover a wide variety of approaches to study systems development without the active involvement of the researchers. Some approaches study practice directly, e.g., field studies and case studies, whereas others are indirect, based on people's opinions and beliefs, e.g., surveys or interviews. The strengths of this approach are that it focuses on practice and that provides the researchers with a vast repertoire of techniques to structure the process and the findings. The weakness is that it separates research from practice. The researchers observe and interpret the actions and beliefs of practitioners and the practitioners do not take active part in the research process. Most of the empirical literature on systems development is based on practice studies (e.g., Aaen et al. 991; Bansler and Bødker 1993; Benbasat, Dexter, and Mantha 1980; Boehm and 
Papaccio 1988; Boland and Day 1982; Ciborra and Lanzara 1994; Curtis, Krasner, and Iscoe 1988; Elam et al. 1987; Gould and Lewis 1985; Kozar 1993; Krasner, Curtis, and Iscoe 1987; Madabusyhi, Jones and Price 1993; Markus 1983; McKeen 1983; Necco, Gordon, and Tsai 1987; Stolterman 1992; Tan 1994; Waltz, Elam, and Curtis 1993; White 1984; White and Leifer 1986).

The SPI project was basically organized as an action research effort to gain optimal conditions for interacting closely with practice and to support close collaboration between practitioners and researchers (Baskerville and Wood-Harper 1996). This basic approach was, however, complemented with experiments and with practice studies to establish a more complete and solid foundation for producing rigorous research results. Such a combined strategy supports the variety of research goals discussed above and compensates for the greatest weakness of action research: the limited support that it provides for structuring the research process and findings. The action research approach in the SPI project was implemented through the local research groups (see Figures 1 and 2). The agendas of these groups reflected the local SPI initiatives and the groups served as a forum for evaluating SPI practices, for experimenting with new or modified approaches, and for learning about the impact of SPI approaches on practice. Field experiments were then staged as dedicated research initiatives within this setting and focused practice studies were initiated to learn about selected SPI practices and their impact on the organization. Some examples will illustrate this combined approach.

The major challenge faced by the SPI initiative in one of the participating organizations was to motivate the systems developers, and in particular the project managers, to commit themselves to improvement efforts. Traditional SPI initiatives are based on normative models (e.g., Emam, Drouin, and Melo 1998; Kuvaja 1994; Paulk et al. 1993), but none of these models were considered useful by the SPI group or the developers. The SPI group, therefore, decided to use problem diagnosis techniques rather than assessments based on general models to learn what the developers considered to be key problems. This research initiative is documented in Iversen, Nielsen, and Nørberg (1998) and is primarily based on action research as proposed by Checkland (1981; Checkland and Scholes 1990).

Each improvement project that is initiated as part of an SPI initiative is facing a complex and often quite risky task, for example to develop, implement, and institutionalize processes to support subcontract management in the organization. The SPI group in one of the organizations wanted to develop tools that could support specific improvement projects in managing risks, thereby minimizing the chance of failure. A dedicated risk management tool for improvement projects was, therefore, developed based on the experiences from that organization in combination with insights from the SPI literature. The resulting tool is documented in (Iversen, Mathiassen, and Nielsen 1999) and the underlying research approach is primarily a field experiment.

Some events during the course of the SPI project were considered so interesting that they attracted special attention. One such case was the implementation of a metrics program to help the organization measure the effects of their improvement efforts. A focused study of this particular case was based on the "natural traces" of the SPI program, such as project plans, meeting minutes, and memos. In addition to this, we tape-recorded the monthly meetings in each local research group as well as some of the working sessions and workshops to collect supplementary data to be used in dedicated and focused 
research initiatives. The relevant segments for the metrics program were transcribed. The case and the lessons learned were published (Iversen and Mathiassen 2000) based on a combination of direct and indirect practice studies.

We see in these examples how a variety of research approaches are used in dedicated research initiatives within the larger project. The SPI project can, from this point of view, be seen as a collaborative space in which specific and dedicated research initiatives are formed to report (1) key lessons from selected parts of the action research activities, (2) proposals based on field experiments that are designed to provide local support, and (3) insights from practice studies of events that emerge as interesting or surprising cases. These three types of research initiatives are exemplified above and they are initiated based on the agendas of the local research groups (see Figure 1). The agenda of the researchers' forum is, however, broader. It includes classical concerns, in which SPI is seen as one instance of technology-related organizational change, and it involves theoretical issues and the use of reference disciplines. Therefore, nsights from practice were also used in the SPI project as inspiration for theoretical studies. A few examples illustrate these theoretical activities.

The SPI literature is extensive but rather practical, with little concern for fundamental research questions. In the SPI project, we had many discussions on the identity and boundaries of the SPI approach as described in the literature. We found no explicit, shared understanding of SPI as a strategy for change in systems development organizations. Based on our practical experiences, we decided to survey the SPI literature to explicate important underlying assumptions and related strategies for change (Aaen et al. 2000).

There are also only a few, rather weak, relations between the SPI literature and relevant reference disciplines. It is, therefore, interesting to interpret SPI experiences using contemporary frameworks from other research areas. One such example is the use of Nonaka's (1994) theory of knowledge creation to understand better how tacit and explicit forms of knowledge can be combined in software organizations and how one can support interaction between individual, group, and organizational knowledge creation processes (Arent and Nørbjerg 2000). Such studies serve to interpret and inform SPI practices and they often provide interesting examples for the reference discipline in question.

Other theoretical contributions from the SPI project are based on subjective/argumentative approaches (Galliers 1991; Galliers and Land 1987). SPI is typically based on a rather narrow view of the systems development process, e.g., from the time a contract is signed until a software system is delivered, and the main concern is to improve processes within the software organization. Bjerknes and Mathiassen (2000) reflect on the nature of well-functioning customer-supplier relations, evaluate those SPI models that are concerned with improved customer relations, and propose specific initiatives to improve the collaboration between customer and supplier organizations. Such initiatives were subsequently implemented in one of the participating organizations. Hence, the research inspired innovative activities that could lead to alternative SPI strategies. 


\section{Research Results}

Collaborative practice studies, as I have discussed them here, are both practice- and research-driven and serve general knowledge interest as well as knowledge interests that are specific for the participating organizations. The results of such efforts are, therefore, of a more diverse nature than those of conventional research projects.

There was a strong inclination in the SPI project to focus on practical results. The rationale to participate was, from the point of view of the software organizations, to engage in collaborative activities that could lead to improved systems development performance and that could stimulate learning within the organization. It goes without saying that actual improvements in processes, infrastructure, and competencies were the key success criteria for the local SPI groups. This constant pressure to focus on practical results implies that research results tend to have secondary priority. The project was, from the very start, based on a shared commitment between the involved organizations, the individual practitioners, and the researchers to build new knowledge that could be published as a contribution to the body of knowledge on systems development. This commitment was maintained by having research issues integrated into the agendas of all groups in the project organization (cf. Figure 1).

Conventional research publications played an important role in the SPI project. Three Ph.D. studies were carried out as part of the project and more than 30 papers, addressing a variety of issues, were published. The important difference in relation to more conventional research projects was that practitioners were included as an important target group for the project. First, more than 10 papers with results from the project were published at conferences or in journals mainly for practitioners (e.g., Jakobson 1998; Johansen and Mathiassen 1998; Vinter 1998). Second, it was decided to publish key lessons from the project in a book titled Learning to Improve. Each chapter in the book presents lessons on SPI from the project, it is written with a practitioners orientation, the foundation is academically sound, based on documented research results from the project, and most of the chapters are coauthored by researchers and practitioners. Papers published in IEEE Software were used as model examples for each chapter and an editor from that journal was engaged to guide the authors and facilitate the editing process.

Professional Systems Development: Experiences, Ideas, and Action (Andersen et al. 1986, 1990), Quality Management in Systems Development (Bang et al. 1991), and Object Oriented Analysis and Design" (Mathiassen et al. 1997) are examples from previous projects illustrating that publication for practitioners is given high priority in this research tradition. There is a sound rationale for pursuing such a strategy in practice research. The researchers are constantly challenged to develop and express results they believe to be useful in practice. Practitioners study the contributions, they attempt to use them, and that reveals strengths and weaknesses of the published results. The research contributions are in this way instrumental in establishing and maintaining a dialogue between research and practice that goes beyond specific research projects. Such a dialogue serves to test and further develop new knowledge, it plays a major role in developing higher education within our discipline, and it helps build an image of the researcher as actively contributing to improved professional practices. This, in turn, makes it considerably easier to establish new collaborations with practitioners. 
Unfortunately, such research contributions are given quite low, and in some cases no, priority in making career decisions within the established research community. The incentive to publish for practitioners is, therefore, minimal and a simple cost/benefit analysis will lead most researchers to the conclusion that it is not worthwhile to become engaged in collaborative practice studies. In that way, we risk isolating ourselves as an appendix to the Information Systems profession instead of being a major force in strengthening its position in society. We should not, of course, stop our efforts to mature as a respected research discipline with high quality journals and research conferences. But we should take care to combine these ongoing initiatives with modified incentive schemes, intensified collaboration with practitioners, and more publications that address practical concerns. That will help us develop new knowledge that will prove to be relevant and it will strengthen our position within the profession and society in general.

\section{Research and Practice}

Collaborative practice research is not merely a way to organize and conduct research. Underlying the specifics of the SPI project is a coherent view of practice, of research, and of the relations between the two. This view is part of a research tradition that has been developed over the past 20 years. The tradition has been discussed as "the ordinary work practices approach" (Hirschheim and Klein 1992) or "the professional work practices approach" (Hirschheim, Klein and Lyytinen 1995a, 1995b; Iivari and Lyytinen 1997). I have presented the underlying perspective as "Reflective Systems Development" (Mathiassen 1998a, 1998b) to acknowledge the relation to Schön's (1983) ideas on how professionals think in action and to stress the intrinsic relation between research and practice. The SPI project should be seen as an effort to further develop this tradition by addressing some of its weaknesses, e.g., a too simplistic view of what it takes to improve practice and lack of an explicit notion of what it means to change practices to the better (Hirschheim, Klein and Lyytinen 1995a, 1995b).

Reflective systems development is illustrated in Figure 5 based on Checkland's notion of the experience-action cycle (Checkland and Scholes 1990). The challenges and opportunities involved in systems development practice are considered the starting point for systems development research. Research activities yield experience-based knowledge that leads to new, and hopefully improved, practices. The knowledge that is developed in this process is both interpretive and normative. Part of it remains local, individual, and even tacit, while other parts are explicated and made publicly available as systems development guidelines, professional books, and research contributions. The research activity is primarily informed by systems development practice, but supported by various reference disciplines (e.g., design theory, organization science, management science, and philosophy), and by dialectic reflections that help us understand change and the contradictory nature of our discipline (Robey 1995). The reference disciplines and dialectics encourage the researchers to go beyond the limited perspectives of approaches such as SPI and to frame their thinking and results in ways that contribute to the building of research-based knowledge. 


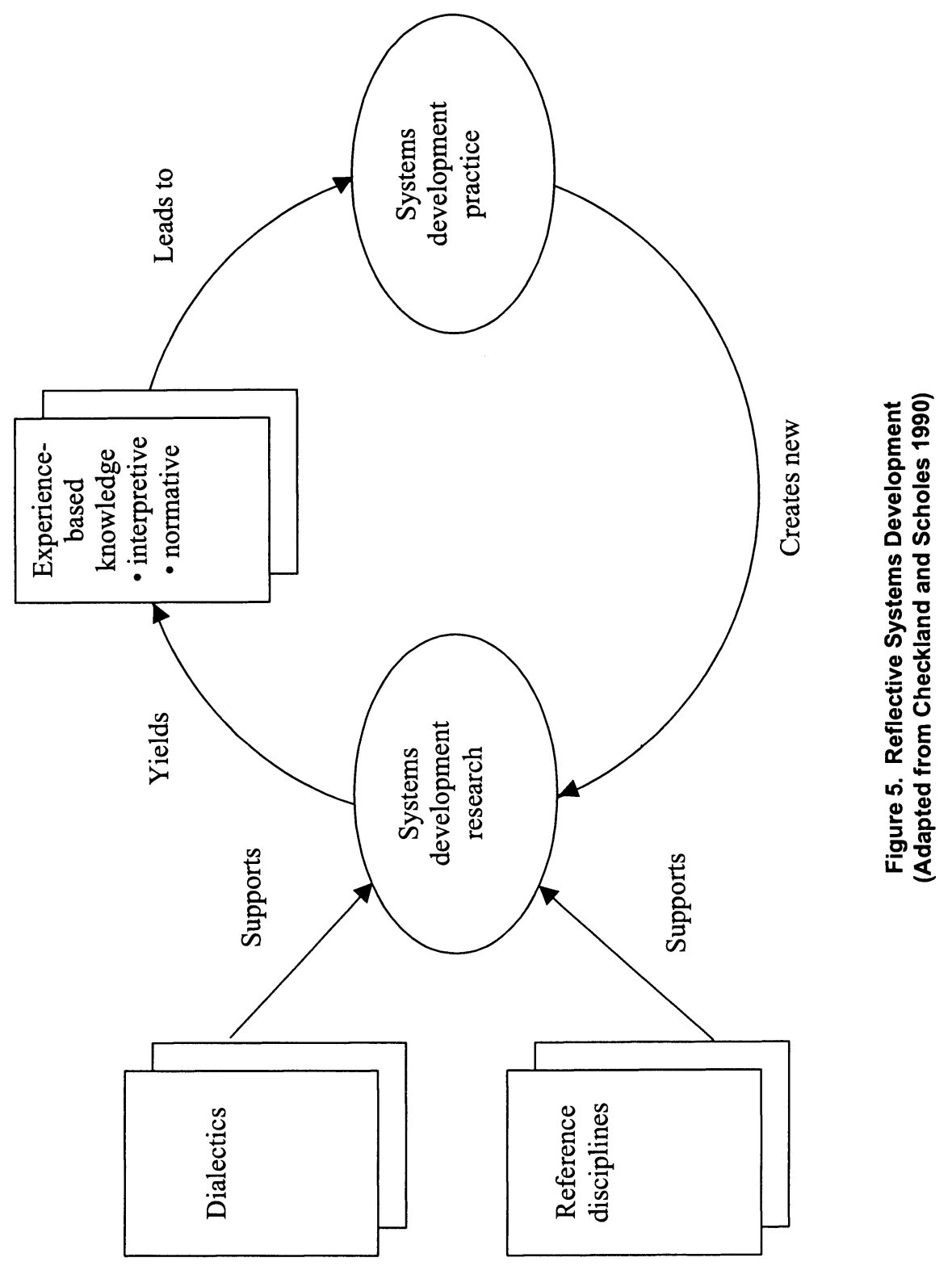


Reflective systems development expresses one, coherent view of practice and research with two different modes of inquiry, a research and a practice mode. This is expressed in Table 1 based on Checkland's ideas on how intellectual frameworks are used in relation to specific application areas (Checkland and Scholes 1990, p. 283). The table explicates the different but related purposes of research and practice, the underlying intellectual frameworks, the type of process in which they are applied, and the shared arena to which they are applied.

In this view, research becomes an activity in which practitioners (can) participate and collaborate with researchers.

The practitioner does not function as a mere user of the researcher's product. He reveals to the reflective researcher the ways of thinking that he brings to his practice, and draws on reflective research as an aid to his own reflection-in-action. Moreover, the reflective researcher cannot maintain distance from, much less superiority to, the experience of practice...he must somehow gain an inside view of the experience of practice. [Schön 1983, p. 323]

This view of research implies and builds on a complementary view of practice in which reflection and learning are key elements. Systems developers must, in addition to mastering a repertoire of general methods and tools, know how to cope with the specific environment in which they work. Many situations involve uncertainty, instability, uniqueness, and contradictions and they require an ability to go beyond the relatively safe territory of general professional knowledge. Systems developers must open their minds and engage in reflections and dialogues to generate the necessary insights into the situation at hand.

\section{Table 1. Reflective Systems Development as an Approach to Research and Practice}

\begin{tabular}{|l|l|l|}
\hline Purpose & Research & Practice \\
\hline & $\begin{array}{l}\text { to develop knowledge to under- } \\
\text { stand, support, and improve } \\
\text { practice as part of the ongoing } \\
\text { professional development }\end{array}$ & $\begin{array}{l}\text { to develop computer-based } \\
\text { information systems as part of } \\
\text { the ongoing transformation of } \\
\text { organizations and society }\end{array}$ \\
\hline Framework & $\begin{array}{l}\text { dialectics } \\
\text { reference disciplines }\end{array}$ & $\begin{array}{l}\text { systems development theory } \\
\text { systems development methods }\end{array}$ \\
\hline Process & action research & reflection-in-action \\
\hline Arena & systems development practice & systems development practice \\
\hline
\end{tabular}

From this point of view, the SPI project is an attempt to practice reflective systems development as a close collaboration between researchers and practitioners. I have discussed the project from a researcher's perspective and in the process provided concepts and experiences that can be used to organize similar initiatives. The discussion can be summarized as a number of lessons. 
- Lesson 1: Implement a full learning cycle of understanding, supporting, and improving practice. Understanding, supporting, and improving expresses the basic knowledge interests involved in studying practice. Dedicated research initiatives will have different emphasis, but it is important to organize the overall project so that it includes full learning cycles in which our understanding of present practices are confronted with explorations of possible alternatives to form new, and hopefully improved, practices.

- Lesson 2: Organize the project as a loosely coupled system of related agendas. Research collaboration with practitioners involves a multiplicity of partly contradictory goals. Research projects should be organized to support diversity, but at the same time function as a shared space in which dedicated research initiatives can be formed as new opportunities emerge. It is particularly important to have separate, interacting agendas for local involvement and detached research.

- Lesson 3: Combine action research, experiments, and practice studies. Action research should be used as the basic form to establish a close relation to practice, but whenever feasible and useful it should be supplemented with experiments and practice studies. Such a combined strategy supports the variety of research goals involved and helps establish a useful balance between rigor and relevance.

- Lesson 4: Establish a basic documentation system to support longitudinal practice studies. The danger in action research is to become too involved in the problems of practice. Longitudinal field research has been developed in response to this challenge emphasizing the need to establish systematic documentation efforts involving indepth interviews, documentary and archive data, and observational and ethnographical material (Nielsen 1999; Pettigrew 1990). Such a documentation system serves as the backbone for organizing dedicated research initiatives that are focused on particular events.

- Lesson 5: Facilitate collaboration in dedicated research initiatives. Research projects should offer opportunities for establishing shifting patterns of collaboration between the researchers involved and between researchers and practitioners. Such patterns are established as interesting issues emerge and new, dedicated research initiatives are formed. Each new initiative involves specific actors and is based on its own combination of research methods to suit the task.

- Lesson 6: Combine scientific publication with publications targeting practitioners. Traditional research publications should be supplemented with publications that inform practitioners about research results. Such publications challenge the researchers to evaluate the relevance of their efforts and are instrumental in maintaining a dialogue between researchers and practitioners beyond the specific project.

- Lesson 7: Engage yourself fully, but only for a while. Collaborative practice research as described here offers good opportunities to develop relevant research 
results, but it requires a dedicated effort involving both research work and organizational work. During a project, it is necessary to spend a major effort on the collaboration. After the project, it is advisable to return to a more traditional activity pattern, to reflect on the experiences from the project, and to publish more of the insights that were gained during the project.

These lessons are meant as inspiration for those having the opportunity and the motivation to engage in collaborative practice research. Such efforts are, however, difficult to create and demanding to manage. This is partly because of the diverse and contradictory nature of the interests and goals involved. However, in many cases, it is also because our institutional settings and incentive schemes do not encourage researchers to engage in close collaboration with practitioners (Lyytinen 1999).

\section{Acknowledgments}

This research has been partially sponsored by the Danish National Centre for IT Research. I wish to thank the software organizations, practitioners, and researchers participating in the Danish SPI project. I also want to thank the associate editor and the anonymous reviewers for many valuable suggestions.

\section{References}

Aaen, I., Siltanen, A., Sørensen, C., and Tahvanainen, V.-P. "A Tale of Two Countries: CASE Experience and Expectations," in The Impact of Computer Technologies on Information Systems Development, K. E. Kendall, K. Lyytinen, and J. I. DeGross (eds.). Amsterdam: North-Holland, 1992.

Aaen, I., Arent, J., Mathiassen, L., O. Nwgenyama, O. "A Conceptual MAP of Software Process Improvement," The Computer Journal, 2000, forthcoming.

Andersen, C. V., Arent, J., Bang, S., and Iversen, J. "Project Assessments: Supporting Commitment, Participation, and Learning in SPI," in Proceedings of Thirty-third Hawaii International Conference on System Sciences. Los Alamitos, CA: IEEE Computer Society, 2000.

Andersen, N. E., Kensing, F., Lassen, M., Lundin, J., Mathiassen, L., Munk-Madsen, A., and Sørgaard, P. Professional Systems Development. Experiences, Ideas, and Action. Copenhagen: Teknisk Forlag (in Danish), 1986.

Andersen, N. E., Kensing, F., Lassen, M., Lundin, J., Mathiassen, L., Munk-Madsen, A., and Sørgaard, P. Professional Systems Development. Experiences, Ideas, and Action. Englewood Cliffs, NJ: Prentice-Hall, 1990.

Applegate, L. M. "Rigor and Relevance in MIS Research," MIS Quarterly (23:1), 1999.

Arent, J., and Nørbjerg, J. "SPI as Organizational Knowledge Creation: A Multiple Case Analysis," in Proceedings of Thirty-third Hawaii International Conference on System Sciences. Los Alamitos, CA: IEEE Computer Society, 2000.

Argyris, C., and Schön, D. Organizational Learning. Reading, MA: Addison-Wesley, 1978.

Avison, D. E., and Wood-Harper, A. T. "Information Systems Development Research: An Exploration of Ideas in Practice," The Computer Journal (34:2), 1991. 
Avison, D., Lau, F., Myers, M., and Nielsen, P. A. “Action Research: Making Academic Research Relevant," Communications of the ACM (42:1), 1999.

Bang, S., Efsen, S., Hundborg, P., Janum, H., Mathiassen, L., and Schultz, C. Quality Management in Systems Development. Copenhagen: Teknisk Forlag. (in Danish), 1991.

Bansler, J., and K. Bødker "A Reappraisal of Structured Analysis. Design in an Organizational Context," ACM Transactions on Information Systems (11:2), 1993,

Basili, V. R., and Weiss, D. M. "A Methodology for Collecting Valid Software Engineering Data," IEEE Transactions on Software Engineering (10), 1984.

Basili, V. R., Selby, R. W., and Hutchens, D. H. "Experimentation in Software Engineering," IEEE Transactions on Software Engineering (12), 1986.

Baskerville, R., and Wood-Harper, A. T. "A Critical Perspective on Action Research as a Method for Information Systems Research," Journal of Information Technology (11), 1996.

Baskerville, R. L., and Stage, J. "Controlling Prototype Development Through Risk Management," MIS Quarterly (20:4), 1996.

Benbasat, I., Dexter, A. S., and Mantha, R. W. "Impact of Organizational Maturity on Information System Skill Needs," MIS Quarterly (4:1), 1980.

Benbasat, I., and Zmud, R. W. "Empirical Research in Information Systems: The Practice of Relevance," MIS Quarterly (23:1), 1999.

Bjerknes, G. "Dialectical Reflection in Information Systems Development," Scandinavian Journal of Information Systems (3), 1991.

Bjerknes, G., and Bratteteig, T. "User Participation and Democracy: A Discussion of Scandinavian Research on Systems Development," Scandinavian Journal of Information Systems (7:1), 1995.

Bjerknes, G., and Mathiassen, L. "Improving the Customer-Supplier Relation in IT Development," in Proceedings of Thirty-third Hawaii International Conference on System Sciences. Los Alamitos, CA: IEEE Computer Society, 2000.

Boehm, B. W., Gray, T. E., and Seewaldt, T. "Prototyping versus Specifying: A Multiproject Experiment," IEEE Transactions on Software Engineering (10:3), 1984.

Boehm, B. W., and Papaccio, P. N. "Understanding and Controlling Software Costs," IEEE Transactions on Software Engineering (10:4), 1988.

Boland, R. J. "The Process and Product of System Design," Management Science (24:9), 1978.

Boland, R. J., and Day, W. "The Process of System Design: A Phenomenological Approach," in Proceedings of the Third International Conference on Information Systems, M. J. Ginzberg and C. A. Ross (eds.), Ann Arbor, Michigan, 1982.

Boland, R. J., and Hirschheim, R. A. (eds.). Critical Issues in Information Systems Research. Chichester: John Wiley, 1987.

Cash, J. I., Benbasat, I., Kraemer, K. L., and Lawrence, P. R. (eds.). The Information Systems Research Challenge, Volumes 1-3. Boston, MA: Harvard Business School, 1989.

Checkland, P. Systems Thinking, Systems Practice. Chichester: John Wiley, 1989.

Checkland, P., and Scholes, J. Soft Systems Methodology in Action. Chichester: John Wiley, 1990.

Ciborra, C., and Lanzara, G. F. "Formative Contexts and Information Technology: Understanding the Dynamics of Innovation in Organizations," Accounting, Management and Information Technology (4:2), 1994.

Cotterman, W., and Senn, J. Challenges and Strategies for Research in Information Systems Development. Chichester, England: Wiley Series in Information Systems, 1992.

Curtis, B., Krasner, H., and Iscoe, N. "A Field Study of the Software Design Process for Large Systems," Communications of the ACM(31:11), 1988.

Davenport, T. H. Process Innovation-Reengineering Work through Information Technology. Boston, MA: Harvard Business School Press, 1993.

Davenport, T., and Markus, M. L. "Rigor vs. Relevance Revisited: Response to Benbasat and Zmud," MIS Quarterly (23:1), 1999. 
Elam, J. J., Waltz, D. B., Krasner, H., and Curtis, B. “A Methodology for Studying Software Design Teams: An Investigation of Conflict Behaviors in the Requirements Definition Phase," Empirical Studies of Programmers. Second Workshop. Norwood, NJ: Ablex Publishing, 1987.

Emam, K. E., Drouin, J-N., and Melo, W. SPICE: The Theory and Practice of Software Process Improvement and Capability Determination. Los Alamitos, CA: IEEE Computer Society, 1998.

Floyd, C. "A Comparative Evaluation of Systems Development Methods," in Information Systems Design Methodologies. Improving the Practice, T. W. Olle et al. (eds.). Amsterdam: NorthHolland, 1986.

Galliers, R. D. "Choosing Appropriate Information Systems Research Approaches: A Revised Taxonomy," in Information Systems Research: Contemporary Approaches and Emergent Traditions, H-E. Nissen, H. K. Klein, and R. Hirschheim (eds.). Amsterdam: North-Holland, 1991.

Galliers, R. D., and Land, F. F. "Choosing Appropriate Information Systems Research Methodologies," Communications of the ACM (30:11), 1987.

Gould, J. D., and Lewis, C. "Designing for Usability: Key Principles and What Designers Think," Communications of the ACM (28:3), 1985.

Guindon, R., Krasner, H., and Curtis, B. "Breakdowns and Processes During the Early Activities of Software Design by Professionals," Empirtcal Studies of Programmers. Second Workshop. Norwood, NJ: Ablex Publishing, 1987.

Hirschheim, R., and Klein, H. K. "Paradigmatic Influences of Information Systems Development Methodologies: Evolution and Conceptual Advances," in Advances in Computers (33), M. Yovits (ed.). New York: Academic Press, 1992.

Hirschheim, R., Klein, H. K., and Lyytinen, K. Information Systems Development and Data Modeling. Conceptual and Philosophical Foundations. Cambridge, England: Cambridge University Press, 1995a.

Hirschheim, R., Klein, H. K., and Lyytinen, K. "Exploring the Intellectual Structures of Information Systems Development: A Social Action Theoretic Analysis," Accounting, Management and Information Technology (6:1-2), $1995 \mathrm{~b}$.

Humphrey, W. S. "Characterizing the Software Process," IEEE Software (5:5, 1988, pp. 73-79. Humphrey, W. S. Managing the Software Process. Reading, MA: Addison-Wesley, 1989.

Iivari, J., and Lyytinen, K. "Information Systems Research in Scandinavia: Unity in Plurality," in Rethinking Management Information Systems, W. Currie and R. D. Galliers (eds.). London: Oxford University Press, 1997.

Iversen, J., Johansen , J., Nielsen, P. A., and Pries-Heje, J. "Combining Quantitative and Qualitative Assessment Methods in Software Process Improvement," in Proceedings of 1998 European Conference on Information Systems, Aix-en-Provence, France, 1998.

Iversen, J., and Mathiassen, L. "Lessons from Implementing a Metrics Program," in Proceedings of Thirty-third Hawaii International Conference on System Sciences. Los Alamitos, CA: IEEE Computer Society, 2000.

Iversen, J., Mathiassen, L., and Nielsen, P. A. "Risk Management in Software Process Improvement," in Proceedings of the 1999 European Conference on Information Systems, Copenhagen, Denmark, 1999.

Iversen, J., Nielsen, P. A., and Nørbjerg, J. "Problem Diagnosis in Software Process Improvement," in Information Systems: Current Issues and Future Changes, T. J. Larsen, L. Levine, and J. I. DeGross (eds.). Laxenburg, Austria: IFIP, 1998, pp. 111-130.

Jakobsen, A. B. "Tricks of Bottom-Up Improvements," IEEE Software, January 1998.

Johansen, J., and Mathiassen, L. "Lessons Learned in a National SPI Effort," EuroSPI'98, Gothenburg, Sweden, 1998. 
Kaiser, K. M., and Bostrom, R. P. "Personality Characteristics of MIS Projects Teams: An Empirical Study and Action-Research Design," MIS Quarterly (6:4), 1982.

Knuth, D. "The Errors of TEX," Software-Practice and Experience (19:1), 1989.

Kozar, K. A. "Adopting Systems Development Methods. An Exploratory Study," Journal of Management Information Systems (5:4), 1993.

Krasner, H., Curtis, B., and Iscoe, N. "Communication Breakdowns and Boundary Spanning Activities of Software Design by Professionals," Empirical Studies of Programmers. Second Workshop. Norwood, NJ: Ablex Publishing, 1987.

Kuvaja, P., Similä, J., Krzanik, L., Bicego, A., Saukkonen, S., and Koch, G. Software Process Assessment and Improvement-The Bootstrap Approach. Oxford: Blackwell, 1994.

Lau, F. "A Review on the Use of Action Research in Information Systems Studies," in Information Systems and Qualitative Research, A. S. Lee, J. Liebenau, and J. I. DeGross (eds.). London: Chapman \& Hall, 1997, pp. 31-68.

Lee, A. "Rigor and Relevance in MIS Research: Beyond the Approach of Positivism Alone," MIS Quarterly (23:1), 1999.

Lee, A. S., Liebenau, J., and DeGross, J. I. (eds.). Information Systems and Qualitative Research. London: Chapman \& Hall, 1997/

Lyytinen, K. "Empirical Research in Information Systems: On the Relevance of Practice in Thinking of IS Research," MIS Quarterly (23:1), 1999.

Madabushi, S. V. R., Jones, M. C., and Price, R. L. "Systems Analysis and Design Models Revisited: A Case Study," Information Resources Management Journal. Winter 1993.

Markus, M. L. "Power, Politics, and MIS Implementation," Communications of the ACM(26:7), 1983.

Mathiassen, L. Reflective Systems Development. Unpublished Dr. Techn. Thesis, Aalborg University, 1998a (available at www.cs.auc.dk/ larsm).

Mathiassen, L. "Reflective Systems Development," Scandinavian Journal of Information Systems (10:1-2), 1998b.

Mathiassen, L., Munk-Madsen, A., Nielsen, P. A., and Stage, J. Object Oriented Analysis and Design. Aalborg: Marko (in Danish; to appear in English), 1997.

McFarlan, F. W. The Information Systems Research Challenge. Boston, MA: Harvard Business School Press, 1984.

McFeeley, B. IDEAL: A User's Guide for Software Process Improvement. Pittsburgh: SEI Handbook, CMU/SEI-96-HB-001, 1996.

McKeen, J. D. "Successful Development Strategies for Business Application Systems," MIS Quarterly (7:3), 1983.

Mumford, E. Designing Human Systems: The ETHICS Method. Manchester, England: Manchester Business School, 1983.

Mumford, E., Hirschheim, R. A., Fitzgerald, G., and Wood-Harper, A. T. (eds.). Research in Information Systems. Amsterdam: North-Holland, 1985.

Munk-Madsen, A. Knowledge About Systems Development. MARS Report No. 13. Aarhus University (in Danish), 1986.

Necco, C. R., Gordon, C. L., and Tsai, N. W. "Systems Analysis and Design: Current Practices," MIS Quarterly (11:4), 1987.

Nielsen, P. A. "Action Research and the Study of IT in Organizations: Making Sense of Change," Department of Computer Science, Aalborg University, 1999.

Nissen, H.-E., Klein, H. K., and Hirschheim, R. A. (eds.). Information Systems Research: Contemporary Approaches and Emergent Traditions. Amsterdam: North-Holland, 1991.

Nonaka, I. "A Dynamic Theory of Organizational Knowledge Creation," Organization Science (5:1), 1994.

Nunamaker, J., Chen, M., and Purdin, T. D. M. "Systems Development in Information Systems Research," Journal of Management Information Systems (7:3), 1991. 
Nygaard, K., and Bergo, O. T. “The Trade Unions. New Users of Research," Personnel Review (4:2), 1975.

Parnas, D. L., and Clements, P. C. "A Rational Design Process: How and Why to Fake It," IEEE Transactions on Software Engineering (12:2), 1986.

Paulk, M. C., Weber, C. V., Curtis, B., and Chrissis, M. B. The Capability Maturity Model: Guidelines for Improving the Software Process. Reading, MA: Addison Wesley, 1993.

Pettigrew, A. M. "Longitudinal Field Research on Change: Theory and Practice," Organization Science (1:3), 1990.

Robey, D. "Theories that Explain Contradiction: Accounting for the Contradictory Organizational Consequences of Information Technology," in Proceedings of the Sixteenth International Conference on Information Systems, J. I. DeGross, G. Ariav, C. Beath, R. Hoyer, and C. Kemerer (eds.), Amsterdam, 1995.

Salaway, G. “An Organizational Learning Approach to Information Systems Development," MIS Quarterly (11:2), 1987.

Selby, R. W, Basili, V. R., and Baker, F. T. "Cleanroom Software Development: An Empirical Evaluation," IEEE Transactions on Software Engineering (13:9), 1987.

Schein, E. K. Organizational Culture and Leadership: A Dynamic View. San Francisco: JosseyBass, 1985.

Schön, D. A. The Reflective Practitioner: How Professionals Think in Action. New York: Basic Books, 1983.

Stolterman, E. "How Systems Designers Think about Design and Methods: Some Reflections Based on an Interview Study," Scandinavian Journal of Information Systems (4), 1992.

Stowell, F., West, D., and Stansfield, M. "Action Research as a Framework for IS Research," in Information Systems: An Emerging Discipline, J. Mingers and F. Stowell (eds.). New York: McGraw-Hill, 1997.

Tan, M. "Establishing Mutual Understanding in Systems Design: An Empirical Study," Journal of Management Information Systems (10:4), 1994.

Vidgen, R., and Braa, K. "Balacing Interpretation and Intervention in Information Systems Research: The Action Case Approach," in Information Systems and Qualitative Research, A. S. Lee, J. Liebenau, and J. I. DeGross (eds.). London: Chapman \& Hall, 1997, pp. 524541.

Vinter, O. "Using Defect Analysis to Initiate the Improvement Process," in EuroSPI'98, Gothenburg, Sweden, 1998.

Vitalari, N. P. "Knowledge as a Basis for Expertise in Systems Analysis: An Empirical Study," MIS Quarterly (9:3), 1985.

Vitalari, N. P., and Dickson, G. W. "Problem Solving for Effective Systems Analysis: An Experimental Exploration," Communications of the ACM (26:11), 1983.

Waltz, D. B., Elam, J. J., and Curtis, B. "Inside a Software Design Team: Knowledge Acquisition, Sharing, and Integration," Communications of the ACM (36:10), 1993.

White, K. B. "MIS Project Teams: An Investigation of Cognitive Style Implications," MIS Quarterly (8:2), 1984.

White, K. B., and Leifer, R. "Information Systems Development Success: Perspectives from Project Team Participants," MIS Quarterly (10:3), 1986.

Wynekoop, J. L., and Russo, N. L. "System Development Methodologies: Unanswered Questions and the Research-Practice Gap," in Proceedings of the Fourteenth International Conference on Information Systems, J. I. DeGross, R. P. Bostrom, and D. Robey (eds.), Orlando, Florida, 1993. 


\section{About the Author}

Lars Mathiassen is a professor in the Computer Science Department of Aalborg University (Denmark). His research interests are within Software Engineering and Information Systems. He has published several books and papers on systems development, object-orientation, risk management, and the philosophy of computing. More details are available at www.cs.auc.dk/ larsm. Lars can be contacted by e-mail at larsm@cs.auc.dk. 